\title{
openheart Are drug-eluting stents any better than bare metal? New evidence in non-ST- elevation acute coronary syndrome
}

\author{
Rahul Bahl
}

To cite: Bahl R. Are drugeluting stents any better than bare metal? New evidence in non-ST-elevation acute coronary syndrome. Open Heart 2016;3:e000536. doi:10.1136/openhrt-2016000536

Accepted 1 November 2016

\section{SLinked}

- http://dx.doi.org/10. 1136/openhrt-2016-000455

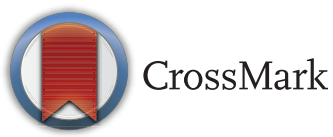

Open Heart, London, UK

Correspondence to Dr Rahul Bahl;

rahulbahl2004@hotmail.com
The management of acute coronary syndrome (ACS) has benefitted from the widespread use of evidence-based, protocoldriven management. This is particularly the case in the management of myocardial infarction (MI) with ST elevation (STEMI) where prompt recognition and reperfusion, preferably via percutaneous coronary intervention (PCI) is now a well-established standard of care. The management of ACS without ST elevation (NSTEACS) presents a greater challenge in determining optimal therapy for what is potentially a more nuanced and heterogeneous clinical situation. Uncertainty can occur in relation to risk stratification, the optimal timing and strategy for PCI and in the use of bare metal (BMS) versus drug-eluting (DES) stent.

A new study by Remkes $e t a l$ published in Open Heart seeks to address the latter. The question is a relevant one and there have been no randomised trials of DES versus BMS looking specifically at the NSTEACS population. Despite seeming to have a milder form of acute coronary disease, with relative rather than total occlusion of a coronary artery, patients with NSTEACS have similar rates of mortality, readmission and revascularisation as patients with STEMI. ${ }^{2}$ This demonstrates that this population tends to be older, with more complex coronary disease, more coronary risk factors and greater comorbidity.

Remkes et al have provided some highquality data to fill this gap in the evidence base. They report a randomised, multicentre trial with blinding of operator and outcome assessors and independent assessment of clinical and angiographic outcomes. It is a substudy of their ELISA-3 trial into immediate versus delayed revascularisation in patients with NSTEACS with high-risk characteristics. However, it also includes a further registry of patients who consented to clinical but not angiographic follow-up or who were not eligible for ELISA-3. Consequently, 178 patients were included for 9-month angiographic follow-up with a further 296 randomised patients also contributing to 2-year clinical outcomes.

The angiographic outcome, for which the study was powered showed a significantly lower rate of restenosis with DES compared with BMS (minimal lumen diameter 2.37 \pm 0.63 vs $1.84 \pm 0.62 \mathrm{~mm}, \mathrm{p}<0.001)$. Rates of binary restenosis were much lower at $1.9 \%$ vs $16.7 \%(p=0.01)$. Among the clinical outcomes, there was a significant reduction in target vessel revascularisation (TVR) with DES at 2 years ( $4 \%$ vs $10.4 \%, \mathrm{p}=0.009)$. Differences in the rate of major adverse cardiovascular events and stent thrombosis (ST) did not reach statistical significance though the study was not powered for these.

Overall, then, this trial seems to provide good evidence supporting the current preference for DES in this setting. ${ }^{3}$ Superior performance of the stent over time due to the antiproliferative effect of the stent coating translates into a lower rate of repeat angioplasty or coronary artery bypass surgery for the vessel. There may even be small but not statistically detectable benefits for clinical outcomes such as mortality and repeat MI. However, it can be dangerous to extrapolate from proxy outcomes (angiographic restenosis) to those of greater importance. The data from this study should therefore be interpreted in light of some further recently published work.

The NORSTENT trial was a large multicentre randomised trial of DES versus BMS in all clinical settings (stable coronary artery disease, NSTEACS and STEMI). ${ }^{4}$ In total, 9013 patients were randomised and clinical follow-up was for 6 years. In keeping with the ELISA-3 substudy, rates of TVR were lower with DES $(5.3 \%$ vs $10.3 \%, \quad \mathrm{p}<0.001)$. However, despite this, there was no overall difference in rates of mortality or MI. 
Some differences between the studies should be acknowledged. Most obviously, NORSTENT was open to all presentations and so the headline results are not specific to the NSTEACS population. There were also more stringent exclusion criteria with this study. In particular, the largest number of patients were excluded due to having had a previous coronary stent or due to being on warfarin. NORSTENT may therefore represent a relatively less complex or less comorbid population who might be expected to have a better outcome. Despite these concerns, the results are compelling. The findings are stable across subgroups by clinical presentation and the size of the population studied and the length of follow-up gives the trial the statistical power to consider clinical outcomes.

The new evidence has several implications for the choice between DES and BMS in NSTEACS. For one, the current generation of DES does not appear to have an increased risk of stent thrombosis compared with BMS where the aim is for 9 months to 1 year of dual antiplatelet therapy following PCI. Neither study showed a difference in this outcome. In patients where there is a clear risk of life-threatening bleeding, particularly gastrointestinal or intracranial haemorrhage, then there may still be a case for use of BMS as there is more clinical experience in stopping the second antiplatelet agent early. The second implication to consider is the choice from the patient's perspective. Even without a difference in mortality or MI, if DES gives a lower risk of needing a repeat procedure (usually another PCI) then it would normally be preferable to BMS. The problem with this is that the difference appears small. NORSTENT reports that 30 patients would have to receive DES to prevent one additional TVR in 6 years. This leads to the final implication. Health systems need to consider whether the additional performance offered by DES is affordable on the basis of this improvement, including the additional cost of the technology and differences in quality of life for patients treated with it. Health economic analysis of the latest studies will be interesting here.

Overall, it appears that health economics will be increasingly influential in the use of new methods and technology in this area of clinical practice. The era of early advanced management in ACS and aggressive preventative medical therapy has led to a situation where it is difficult for new technologies and methods to demonstrate clear and important improvements in outcomes for patients. It is reasonable to expect that similar questions will arise with future developments including the next generation of DES.

Competing interests None declared.

Provenance and peer review Commissioned; internally peer reviewed.

Open Access This is an Open Access article distributed in accordance with the Creative Commons Attribution Non Commercial (CC BY-NC 4.0) license, which permits others to distribute, remix, adapt, build upon this work noncommercially, and license their derivative works on different terms, provided the original work is properly cited and the use is non-commercial. See: http:// creativecommons.org/licenses/by-nc/4.0/

\section{REFERENCES}

1. Remkes WS, Badings EA, Hermanides RS, et al. A randomised comparison of drug-eluting vs. bare metal stenting in patients with non-ST elevation myocardial infarction. Open Heart Published Online First: 17 Nov 2016. doi:10.1136/openhrt-2016-000455

2. Montalescot G, Dallongeville J, Van Belle E, et al. STEMI and NSTEMI: are they so different? 1 year outcomes in acute myocardial infarction as defined by the ESC/ACC definition (the OPERA registry). Eur Heart $J$ 2007;28:1409-17.

3. Windecker S, Kolh P, Alfonso F, et al., Authors/Task Force members. 2014 ESC/EACTS Guidelines on myocardial revascularization: the Task Force on Myocardial Revascularization of the European Society of Cardiology (ESC) and the European Association for Cardio-Thoracic Surgery (EACTS) Developed with the special contribution of the European Association of Percutaneous Cardiovascular Interventions (EAPCI). Eur Heart $J$ 2014;35:2541-619.

4. Bønaa $\mathrm{KH}$, Mannsverk J, Wiseth R, et al. Drug-eluting or bare-metal stents for coronary artery disease. N Engl J Med 2016;375:1242-52. 